\title{
An Unconventional Example of Big Data: BIST-100 Banking Sub- Index of Turkey
}

Çelik, Sadullah ${ }^{a}$ and İşbilen, Elif ${ }^{b}$

${ }^{\mathrm{a}}$ Department of Economics (Eng.), Marmara University, Turkey, ${ }^{\mathrm{b}}$ Department of Economics, Marmara University, Turkey.

\begin{abstract}
This paper applies Big Data concept to an emerging economy stock exchange market by examining the relationship between price and volume of the Banking index in BIST-100. Stock markets have been commonly analyzed in big data studies as they are one of the main sources of rich data with recordings of hourly and minutely transactions. In this sense, nowcasting the economic outlook has been related to the fluctuations in the stock exchange market as news from companies open to public became important sources of changes in expectations for economic agents. However, most of the previous studies concentrated on the main stock market indices rather than the major sub-indices. This study covers the period 13 December 2017 - 12 March 2018, with minute data and approximately 31000 observations for each of the 11 bank stocks. The effects of stock market movements on exchange rates and interest rates are also examined. The methodologies used are frequency domain Granger causality of Breitung and Candelon (2006) and wavelet coherence of Grinsted et al. (2004). The main finding is the supremacy of the banking index as it seems to have great influence on economic fluctuations in Turkish economy through other high frequency variables and the households' expectations.
\end{abstract}

Keywords: Big data; emerging market; banking stock market index; nowcasting. 